\title{
ApONTAMENTOS SOBRE UMA CANÇÃO para teatro: "Funeral de um lavrador"
}

\section{Walter GarcIa}

Universidade de São Paulo

Resumo

O artigo estabelece relações entre Morte e vida severina, de João Cabral de Melo Neto, e "Funeral de um lavrador", canção composta por Chico Buarque para a montagem do poema pelo grupo do Teatro da Universidade Católica de São Paulo (Tuca) em 1965, e apresenta algumas questões sobre a canção de protesto composta para teatro, na década de 1960, assim como sobre sua pertinência nos dias de hoje.

\section{Abstract}

This article establishes relationships between João Cabral de Melo Neto's Morte e vida Severina and "Funeral de um lavrador", a song by Chico Buarque composed for the dramatic performance of that work by the group of Teatro da Universidade Católica de São Paulo (Tuca) in 1965, and presents a discussion about the protest song composed for the theatre in the 1960s, as well as about its relevance today.

\author{
Palavras-chave \\ Canção e \\ teatro; música \\ popular \\ brasileira; \\ poesia moderna \\ brasileira.
}

\author{
Keywords \\ Song and \\ theatre; \\ Brazilian \\ popular music; \\ modern \\ Brazilian poetry.
}


canção "Funeral de um lavrador" foi composta por Chico Buarque de Holanda em 1965 para Morte e vida severina, de João Cabral de Melo Neto. ${ }^{\text {Trata- }}$ va-se de uma encomenda do grupo do Teatro da Universidade Católica de São Paulo (Tuca). Daí o cancionista recordar, já em 2005, que "o grupo todo era de amadores", incluindo ele mesmo, ainda estudante da Faculdade de Arquitetura e Urbanismo da USP. "Foi um atrevimento, aliás, porque musicar João Cabral de Melo Neto, hoje eu não teria coragem. Naquele tempo eu não tinha consciência, então eu topei" . ${ }^{2}$ Outra versão desse atrevimento foi relatada por quem lhe fizera o convite, o escritor e psicanalista Roberto Freire. Em 1965, Freire era o diretor artístico do Tuca. Em 1989, ele disse que Chico Buarque primeiro recusara a tarefa, afirmando "que musicar João Cabral era demais para ele". ${ }^{3}$ Seja como for, em 2005 Chico Buarque justificou sua falta de consciência, quarenta anos antes, lembrando que o poeta "detestava música". ${ }^{4}$

Sabe-se que a anedota já rendeu letra. Não a Chico Buarque, mas a Caetano Veloso, que lançou "Outro retrato" em 1989. Talvez a anedota deva parte de sua popularidade ao refrão "Minha música vem da/ Música da poesia de um poeta João que/ Não gosta de música". ${ }^{5}$ Mas os próprios versos, com seu gosto pelo paradoxo, apontam para a resposta que, em entrevista de 1994, João Cabral daria à questão sobre "não gostar de música" e sobre tê-la evitado em seus poemas:

${ }^{1}$ Cf. João Cabral de Melo Neto, "Morte e vida severina, Auto de Natal pernambucano, 19541955", in _. Obra completa, org. Marly de Oliveira, $3^{a}$ reimp., Rio de Janeiro, Nova Aguilar, 1999, p. 169-202.

${ }^{2}$ Cf. Chico Buarque, "Extras: Chico fala: Teatro", in Bastidores, direção Roberto de Oliveira. RWR Comunicações/ DirectTV/ EMI, 345542 9, 2005.

${ }^{3}$ Cf. Humberto Werneck, "Gol de letras", in Chico Buarque, letra e música 1, 2. ed., $4^{a}$ reimp., São Paulo, Companhia das Letras, 2000, p. 61.

${ }^{4}$ Cf. Chico Buarque, "Extras: Chico fala: Teatro", op. cit.

${ }^{5}$ Cf. Caetano Veloso, "Outro retrato", in Estrangeiro, Philips/ PolyGram, 838 297-2, 1989. 
Aí é o seguinte: realmente não tenho ouvido para a música, compreende? Só gosto de dois gêneros: o frevo de Pernambuco e o flamenco da Andaluzia. O resto da música não me interessa. Mas o negócio é que música não é só melodia. Música é ritmo também. E minha poesia é musical, no sentido de que é fortemente rítmica. [...] Não se pode dizer isto de toda música, mas em geral ela me faz dormir. E, como dizia Valéry, ele estava sempre à procura não do que o fizesse dormir, mas do que o fizesse despertar. Eu também estou à procura de uma coisa que me acorde, e não de uma que me embale. Você vê, por exemplo, que não tenho poemas cantantes, não tenho poemas de embalar. Procuro uma linguagem em que o leitor tropece, não uma linguagem em que ele deslize. ${ }^{6}$

Em artigo de 1969, Anatol Rosenfeld escreveu que "à música de Francisco Buarque de Holanda a encenação [de Morte e vida severina] deveu efeitos magistrais". ${ }^{7}$ Segundo Roberto Freire, "logo após a estreia do Tuca, Nogueira Moutinho, crítico literário da Folha de S.Paulo, descobriu o segredo de Chico naquele trabalho: a música havia sido extraída do poema e não composta para ele" (grifos do original). A se confiar no testemunho de Freire, João Cabral, "numa conferência que fez na Faculdade de Letras [da Universidade de Lisboa], confirmou as palavras do crítico e ainda foi mais longe": afirmou que não conseguia repetir seus versos "de memória sem as músicas de Chico". E não será desinteressante citar uma segunda anedota que diverge daquela primeira: ainda segundo Roberto Freire, João Cabral "cantou as músicas de seu poema", ao se despedir do grupo do Tuca em Lisboa, em meio a uma "solenidade cômico-musical". 8

Nos limites destes apontamentos - ou seja, sem pretender abordar relações entre música, poesia e teatro para além do que é essencial a "Funeral de um lavrador" -, recorde-se que Morte e vida severina é um "Auto de Natal pernambucano". Portanto, é um poema dramático, uma obra escrita para ser declamada. ${ }^{9}$ Todavia, entre a declamação e o canto, "por maiores que sejam as afinidades", sempre se coloca "uma espécie de abismo" como notou, entre outros, Manuel Bandeira. ${ }^{10}$

${ }^{6}$ Cf. "João Cabral de Melo Neto por José Geraldo Couto", in Adriano Schwartz (org.) Memórias do presente: 100 entrevistas do "Mais!": 1992-2002: Conhecimento das Artes, São Paulo: Publifolha, 2003, p. 156-157. Entrevista publicada originalmente em 22 maio 1994.

${ }^{7}$ Cf. Anatol Rosenfeld, "O teatro brasileiro atual", in __. Prismas do teatro, São Paulo, Perspectiva/Edusp; Campinas, Editora da Unicamp, 1993, p. 156.

${ }^{8}$ Cf. Roberto Freire, "Chico dá samba", Realidade, ano 1, n. 9. São Paulo, Editora Abril, dez. 1966, p. 74. João Cabral de Melo Neto assistiu a Morte e vida severina na França, em abril de 1966, quando a montagem do Tuca recebeu os prêmios de crítica e público no IV Festival de Teatro Universitário de Nancy. Logo a seguir, acompanhou apresentações em Lisboa, Porto e Coimbra. Nessa temporada, Chico Buarque atuou como um dos violonistas (cf. Werneck, "Gol de letras", op. cit., p. 63-64).

${ }^{9}$ Morte e vida severina foi escrito "por encomenda de Maria Clara Machado, para o grupo de teatro Tablado", do Rio de Janeiro. Até a montagem do Tuca, não havia sido encenado. Segundo Humberto Werneck, até assistir ao espetáculo João Cabral "estava certo de que [o poema] não funcionaria no palco - menos ainda com música” (Cf. Werneck, "Gol de letras”, op. cit., p. 63).

${ }^{10}$ Cf. Manuel Bandeira, Itinerário de Pasárgada, 3. ed., Rio de Janeiro, Editora do Autor, 1966, p. 80. A observação se refere a quaisquer "duas artes"; porém, Bandeira comenta nessa passagem, de modo específico, relações entre a palavra e a música. 
Observando-se os versos que serviram a "Funeral de um lavrador", não faltam motivos para o ouvinte, se não tropeçar, ao menos não deslizar com grande facilidade. Trata-se da parte inicial de "Assiste ao enterro de um trabalhador de eito e ouve o que dizem do morto os amigos que o levaram ao cemitério". ${ }^{11}$ Mantendo certa irregularidade no metro dos versos e utilizando mais de uma cadência, o ritmo das seis quadras parece dar privilégio aos "processos de pensar por meio de palavras", ${ }^{12}$ dificultando, ao menos em parte, o predomínio do embalo que, via de regra, dispensa o entendimento intelectual.

Nas seis quadras de João Cabral, há versos com quatro, cinco, seis e sete sílabas. Creio que a alternância desses metros e a variedade de cadências serão mais bem percebidas se apresentadas de modo bem simples: os metros vão representados respectivamente pelas letras A, B, C, D; junto de cada letra, números indicam os diferentes tipos de cadência; e algumas outras possibilidades de declamação são também consideradas.

\begin{tabular}{|c|c|c|c|}
\hline \multirow{4}{*}{ 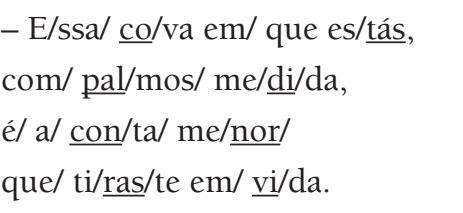 } & \multicolumn{3}{|l|}{$\mathrm{Cl}$} \\
\hline & $\mathrm{B} 1$ & \multirow{3}{*}{ é a/ con/ta/ me/nor/ } & \multirow{3}{*}{ B1 } \\
\hline & $\mathrm{Cl}$ & & \\
\hline & $\mathrm{B} 2$ & & \\
\hline \multirow{4}{*}{$\begin{array}{l}\text { - É/ de/ } \underline{\mathrm{bom}} / \mathrm{ta} / \underline{\mathrm{ma}} / \mathrm{nho} \\
\text { nem/ lar/go/ nem/ fun/do, } \\
\text { é/ a/ par/te/ que/ te/ } \underline{\mathrm{ca}} / \mathrm{be} \\
\text { des/te/ la/ti/fún/dio. }\end{array}$} & $\mathrm{B} 2$ & \multirow[t]{2}{*}{$\underline{\mathrm{E}} / \mathrm{de} / \mathrm{bom} / \mathrm{ta} / \underline{\mathrm{ma}} / \mathrm{nho}$} & \multirow[t]{2}{*}{ B4 } \\
\hline & $\mathrm{B} 1$ & & \\
\hline & D1 & \multirow[t]{2}{*}{ é a/ par/te/que/ te/ ca/be } & \multirow[t]{2}{*}{$\mathrm{C} 2$} \\
\hline & B3 & & \\
\hline \multirow{4}{*}{ 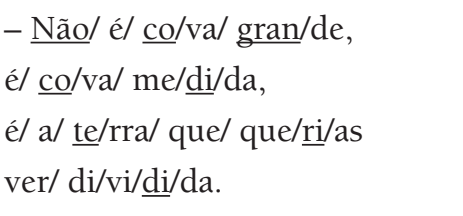 } & B4 & \multirow[t]{2}{*}{ Não/ é/ co/va/gran/de } & \multirow[t]{2}{*}{ B2 } \\
\hline & $\mathrm{B} 1$ & & \\
\hline & $\mathrm{D} 1$ & \multirow[t]{2}{*}{ é a/ te $/$ rra/ que/ que/ri/as } & \multirow[t]{2}{*}{$\mathrm{C} 2$} \\
\hline & Al & & \\
\hline 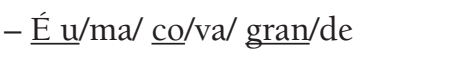 & B4 & \multirow[t]{5}{*}{ É u/ma/ co/va/gran/de } & \multirow[t]{5}{*}{$\mathrm{B} 2$} \\
\hline $\mathrm{pa} / \mathrm{ra} / \mathrm{teu} / \mathrm{pou} / \mathrm{co} / \mathrm{de} / \mathrm{fun} / \mathrm{to}$ & D2 & & \\
\hline mas/ es/ta/rás/mais/ an/cho & $\mathrm{C} 3$ & & \\
\hline que es/ta & $\mathrm{B} 1$ & & \\
\hline - É u/ma/ co/va/gran/de & B4 & & \\
\hline $\mathrm{pa} / \mathrm{ra} / \mathrm{teu} / \mathrm{de} / \underline{\mathrm{fun}} / \mathrm{to} / \mathrm{par} / \mathrm{co}$ & D3 & \multirow[t]{2}{*}{$\mathrm{pa} / \mathrm{ra} / \mathrm{teu} / \mathrm{de} / \mathrm{fun} / \mathrm{to} / \mathrm{par} / \mathrm{co}$} & \multirow[t]{2}{*}{$\mathrm{D} 1$} \\
\hline 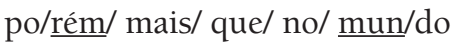 & $\mathrm{C} 2$ & & \\
\hline te/ sen/ti/rás/ lar/go. & B5 & $\underline{\text { te}} /$ sen/ti/rás/ lar/go & B3 \\
\hline
\end{tabular}




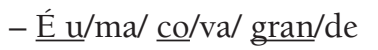

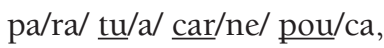

$\mathrm{mas} / \mathrm{a} / \mathrm{te} / \mathrm{rra} / \mathrm{da} / \mathrm{da}$

não/ se/ $\underline{a} / \mathrm{bre} a / \underline{b o} / c a$.
B4

D3

$\mathrm{pa} / \mathrm{ra} / \mathrm{tu} / \mathrm{a} / \mathrm{car} / \mathrm{ne} / \mathrm{pou} / \mathrm{ca}$

D1

B2

B2 não/ se a/bre a/ bo/ca

A fim de melhor apresentar a variedade de cadências, representarei agora "as células métricas pelos algarismos 2, 3 e 4, conforme o número de sílabas que as compõem", baseando-me no estudo Ritmo e poesia, de M. Cavalcanti Proença. ${ }^{13}$ "Célula métrica", sucintamente, é a unidade rítmica determinada pela sucessão de sílabas átonas e tônicas; a extensão de uma "célula métrica" é fixada pela acentuação (principal ou secundária) do verso. Sistematizando os diferentes tipos de cadência, isto é, as diferentes combinações de células métricas que formam cada um dos versos, temos nas seis quadras de João Cabral:

\begin{tabular}{|c|c|c|c|}
\hline & metro & células métricas & exemplo \\
\hline Al & quatro sílabas & 4 & ver/ di/vi/di/da \\
\hline A2 & quatro sílabas & 2,2 & não/ se a/bre a/ bo/ca \\
\hline B1 & cinco sílabas & 2,3 & $\mathrm{com} / \mathrm{pal} / \mathrm{mos} / \mathrm{me} / \mathrm{di} / \mathrm{da}$ \\
\hline B2 & cinco sílabas & 3,2 & que/ ti/ras/te em/ vi/da \\
\hline B3 & cinco sílabas & 1,4 & $\underline{\mathrm{des}} / \mathrm{te} / \mathrm{la} / \mathrm{ti} / \underline{\mathrm{fú}} / \mathrm{dio}$ \\
\hline B4 & cinco sílabas & $1,2,2$ & 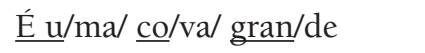 \\
\hline B5 & cinco sílabas & 4,1 & te/ sen/ti/rás/ lar/go \\
\hline $\mathrm{Cl}$ & seis sílabas & 3,3 & $\mathrm{E} / \mathrm{ssa} / \underline{\mathrm{co}} / \mathrm{va} \mathrm{em} /$ que es/tás \\
\hline $\mathrm{C} 2$ & seis sílabas & 2,4 & é a/ te/rra/ que/ que/ri/as \\
\hline $\mathrm{C} 3$ & seis sílabas & 4,2 & mas/ es/ta/rás/mais/ an/cho \\
\hline D1 & sete sílabas & 3,4 & é/ a/ par/te/ que/ te/ ca/be \\
\hline D2 & sete sílabas & 4,3 & $\mathrm{pa} / \mathrm{ra} / \mathrm{teu} / \mathrm{pou} / \mathrm{co} / \mathrm{de} / \underline{\mathrm{fun}} / \mathrm{to}$ \\
\hline D3 & sete sílabas & $3,2,2$ & $\mathrm{pa} / \mathrm{ra} /$ teu/ de/fun/to/ par/co \\
\hline
\end{tabular}

O metro que aparece em maior número, isto é, em quatorze versos, é o de cinco sílabas (redondilha menor). Há nove versos de seis ou de sete sílabas (redondilha maior), e um verso de quatro sílabas. Nessa conta, ignorei as segundas alternativas de declamação. Caso fossem consideradas, os números não mudariam muito (há dois casos de sete ou seis sílabas; um de seis ou cinco sílabas; e um de cinco ou quatro sílabas).

Sobre as alternativas de cadência, vale a pena chamar a atenção para a possibilidade de um "verso duro": ao optar por "te sentirás largo", a declamação reforçará

${ }^{13}$ Cf. M. Cavalcanti Proença, Ritmo e poesia, Rio de Janeiro, Organização Simões, 1955, p. 22. 
o conteúdo pelo necessário tempo entre "sentirás" e "largo". Fazendo o caminho inverso: ao pensar no conteúdo e pretender expressá-lo, a declamação acabará optando pelo "verso duro". ${ }^{14}$ Por outro meio, e no entanto trazendo um ganho semelhante, há a possibilidade de sublinhar as palavras "defunto" e "carne" ao optar pelo acento secundário na quinta sílaba da redondilha maior. De novo fazendo o caminho inverso: ao pensar no conteúdo dos versos condensado nas palavras "defunto" e "carne" e pretender expressá-lo, a declamação acabará optando pela sucessão de células métricas 3,2,2.

Em 1966, Odette Lara e o MPB4 apresentaram a canção em show, dividido com Chico Buarque, na boate Arpège, no Leme. ${ }^{15}$ E Odete Lara gravou "Funeral do lavrador" (sic) para seu disco Contrastes. ${ }^{16}$ No mesmo ano, Nara Leão também incluiu "Funeral de um lavrador" em show na boate Cangaceiro, em Copacabana, e gravou-a para o disco Manhã de liberdade (a censura proibiu a difusão da faixa em rádio). ${ }^{17}$

Dois anos mais tarde, Chico Buarque lançou-a no seu terceiro LP. ${ }^{18}$ Tomarei essa gravação pelo compositor, com participação do grupo MPB4, como referência para estabelecer algumas comparações entre o poema e a letra cantada.

Em síntese, o grande acerto na "extração" da musicalidade do poema decorre da economia de recursos. A linguagem musical, retraindo-se, não prejudica o entendimento da letra. Ao mesmo tempo, a matéria histórica da "cova medida" para o enterro do trabalhador de eito no latifúndio - cova adequada ao "defunto parco", de "carne pouca" -, fica mais bem compreendida pelo modo simples como é cantada. Desse ângulo, pode-se dizer que a reiteração musical espelha as várias repetições com que as quadras de João Cabral se estruturam. Não sem razão, já no texto escrito para o seu primeiro LP, em 1966, Chico Buarque afirmava: "É preciso confessar que à experiência com a música de Morte e vida severina devo muito

${ }^{14}$ O fato de a cadência "te sentirás largo" transformar em tônico um monossílabo átono, no meu ponto de vista, é menos relevante do que o menor relevo que essa forma dá, na declamação, à sensação expressada.

${ }^{15}$ Devo a informação a Mônica Thiele e ao Magro (Antônio José Waghabi Filho), que gentilmente me enviaram, por correio eletrônico, gravação de "Funeral de um lavrador" na boate Arpège. Segundo Magro - que formava o MPB4 junto com Miltinho, Aquiles e Ruy -, participaram ainda do show Luiz Marinho (contrabaixo), Murilo (bateria), Balu (flauta) e Raul de Barros (trombone); Miltinho e Chico Buarque tocaram violão. Ainda segundo Magro, o show chamava-se Meu refrão até "A banda" (Chico Buarque) vencer o II Festival da Música Popular Brasileira, promovido pela TV Record em São Paulo. A partir de então, o show passou a chamar-se Pra ver a banda passar. Não custa lembrar que o primeiro lugar do festival foi dividido com "Disparada" (Théo de Barros e Geraldo Vandré).

${ }^{16}$ Cf. Odette Lara, Contrastes. Disponível em: <http://www.radio.uol.com.br/\#/album/odette-lara/ contrastes/13715>. Acesso em: 27 maio 2011. Segundo Magro, o MPB4 não participou desse disco.

${ }^{17}$ Cf. Sérgio Cabral, Nara Leão: uma biografia, 2. ed., Rio de Janeiro, Lumiar, 2001, p. 123 e 126. Cf. Nara Leão, Manhã de liberdade, Universal, 73145463402/ SET 73145863262, 2002 (reedição em CD do LP lançado em 1966).

${ }^{18}$ Cf. Chico Buarque, Chico Buarque de Hollanda volume 3, Som Livre, 0433-2, 2006 (reedição em CD do LP lançado em 1968). 
do que aí está. Aquele trabalho garantiu-me que melodia e letra devem e podem formar um só corpo". ${ }^{19}$

Na gravação de "Funeral de um lavrador", em 1968, o compositor altera duas palavras - duas alterações irrelevantes. Logo no primeiro verso, canta "Esta cova em que estás" em lugar de "Essa cova em que estás". ${ }^{20}$ Em outros três versos, canta "pra" em vez de "para": "Pra teu pouco defunto"; "Pra teu defunto parco"; "Pra tua carne pouca". Basicamente, a canção é feita da repetição de uma só parte musical. Formada por duas frases melódicas, a parte musical faz cantar uma quadra do poema. Cada frase melódica é construída por dois motivos. Assim, cada verso é entoado com um motivo melódico diferente. Mas o último motivo é uma variação do anterior, o que reduz a variedade. Além disso, as notas rebatidas e a tessitura pouco extensa (de sol\# a mi) também contribuem para que a reiteração de elementos musicais sobressaia na composição.

$\mathrm{Na}$ primeira frase, o motivo melódico inicial (motivo a) desce por graus conjuntos (V-IV-III-II). O perfil descendente com que se entoa o verso, logicamente, introduz de forma adequada o tema da canção. Já o motivo seguinte (motivo b) apresenta os únicos saltos melódicos. Embora sejam modestos (terça menor ascendente; terça maior ascendente e quinta justa descendente, num arpejo de Lá menor), os saltos configuram núcleos sentimentais em meio à característica marcadamente declamatória da melodia, cujo desenho, ao modo de recitativo, não parece querer que o raciocínio do ouvinte adormeça. Na voz de Chico Buarque, a canção como um todo expressa melancolia, seja pela própria dicção do cantor (sob forte influência da dicção de João Gilberto), seja pelo andamento desacelerado, ao qual corresponde o prolongamento de algumas notas. E também expressa sobriedade (em parte, também por efeito da influência de João Gilberto). ${ }^{21}$ Mas há

${ }^{19}$ Idem, Chico Buarque de Hollanda. Som Livre, 0278-2, 2006 (reedição em CD do LP lançado em 1966).

${ }^{20}$ Sem que a modificação deixe de ser irrelevante, e ainda que "essa" indique, segundo a norma culta, um lugar mais próximo à segunda pessoa do discurso, note-se que "Esta cova em que estás" cria uma sonoridade mais interessante para o verso inicial de uma canção.

${ }^{21}$ A influência do trabalho de João Gilberto foi apresentada, de modo interessante, por Chico Buarque no artigo "Nem toda loucura é genial, nem toda lucidez é velha", publicado no jornal Última Hora de 9. dez. 1968: "É certo que se deve romper com as estruturas. Mas a música brasileira, ao contrário de outras artes, já traz dentro de si os elementos de renovação. Não se trata de defender a tradição, família ou propriedade de ninguém. Mas foi com o samba que João Gilberto rompeu as estruturas da nossa canção" (cf. Adélia Bezerra de Meneses, Desenho mágico, 2. ed., São Paulo, Ateliê Editorial, 2000, p. 24-29. Cf. também a nota 24). Não é o caso de abordar, nos limites deste artigo, as articulações entre a canção de protesto da classe média, na década de 1960, e a bossa nova criada em torno de João Gilberto; entretanto, assinale-se que não há uma mera oposição entre as formas. Sobre o assunto, cf. Armando Aflalo, "João vê tudo errado na bossa nova", Jornal do Brasil (Caderno B), 24 abr. 1966, p. 8; Júlio Medaglia, "Balanço da bossa nova", in Augusto de Campos (org.) Balanço da bossa \& outras bossas, 4. ed., São Paulo, Perspectiva, 1986, p. 67-123; Affonso Romano de Sant'Anna, Música popular e moderna poesia brasileira, 3. ed., Petrópolis, Vozes, 1986, p. 222-234). 
traços de indignação, talvez de perplexidade. No plano da melodia, esses traços se concentram nos saltos melódicos do motivo b.

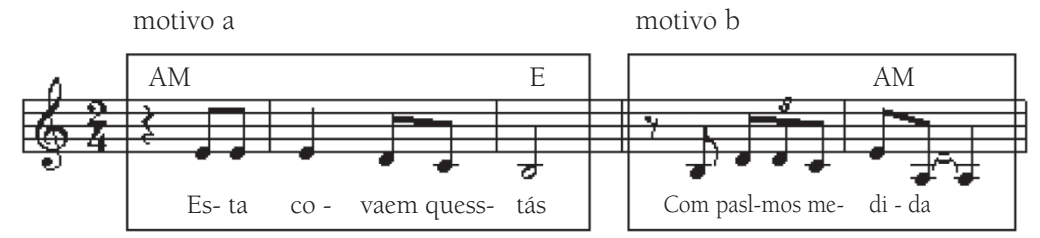

Figura 1 - Primeira frase melódica de "Funeral de um lavrador".

Entre parênteses, note-se que se tomássemos por base a interpretação de Odette Lara, no disco Contrastes, e a de Nara Leão, em Manhã de liberdade, diríamos que a canção, de modo geral, expressa indignação. Ambas as cantoras representam o desagrado pela injustiça social e econômica com mais intensidade do que Chico Buarque. E ambas as dicções não são melancólicas. Há também uma versão para o francês, gravada por Nara Leão. ${ }^{22}$ Mas, nesse caso, escuta-se um acalanto, e a melancolia é doce, diversa da melancolia mais tristonha da dicção de Chico Buarque.

$\mathrm{Na}$ segunda frase de "Funeral de um lavrador", um novo motivo melódico (motivo c) se apresenta, caracterizando-se pela repetição de uma mesma nota. Esse motivo será variado, alterando-se a nota rebatida e também a figura rítmica. Ambos os motivos são arrematados de forma ascendente. Todavia, uma vez que a nota final é a mesma nota inicialmente repetida, é de pouca oscilação o perfil dessa segunda frase.

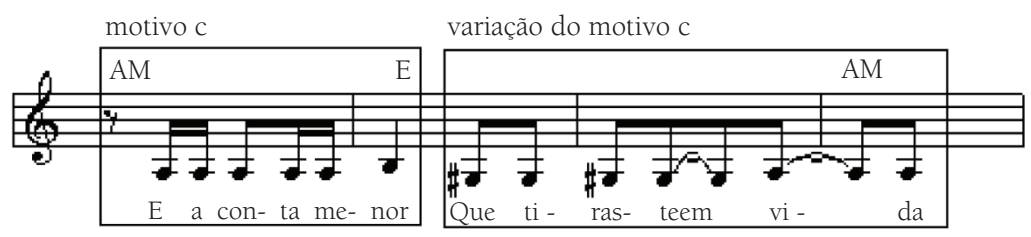

Figura 2 - Segunda frase melódica de "Funeral de um lavrador".

Como se disse, as seis quadras são entoadas com a mesma melodia. Contudo, aquelas diferenças de metro e de cadência com que João Cabral de Melo Neto organizou seus versos quebram um pouco a monotonia do canto, uma vez que a melodia se acomoda a tais diferenças a fim de, inclusive, sempre respeitar a prosódia. Para tanto, em mais de uma passagem, Chico Buarque faz uso da duração

${ }^{22}$ A gravação foi incluída como bônus na reedição em CD do disco Manhã de liberdade. Cf. Nara Leão, op. cit. 
das vogais no auxílio à acentuação das palavras (por exemplo, no verso "te sentirás largo").

Já uma mudança significativa em relação à forma do poema ocorre pela adoção do canto responsorial: ${ }^{23}$ não se escutam sucessivamente "os amigos que o levaram ao cemitério"; mas a cada quadra entoada pelo solista (exceto a última), segue-se a resposta pelo MPB4, isto é, pelo coro, que repete os dois últimos versos com abertura de vozes. Seja por estar mais colado à pulsação rítmica do que o solista, seja pela necessidade de cantar com ritmo mais marcado, o MPB4 contraria a prosódia duas vezes: "estarás mais ancho/ que estavás no mundo"; "porém mais que no mundo/ te sentiras largo". De todo modo, a comunicação dos versos não sai prejudicada.

Ao final, a coda é feita da repetição, por Chico Buarque, de todas as respostas do coro (à exceção de "porém mais que no mundo/ te sentirás largo"), sempre com a segunda frase melódica. Nos versos conclusivos, embora a sobriedade se mantenha, canta-se com sarcasmo o trocadilho, já sarcástico no poema, "mas a terra dada/ não se abre a boca".

Em outra entrevista na qual relembrava Morte e vida severina, em 1999, Chico Buarque afirmou que, diante de seu despreparo, levara a sério a encomenda do Tuca e fizera "um trabalho de pesquisa bastante intenso". Indo à "casa de um pesquisador", ouvira "montanhas de fitas com músicas recolhidas do Nordeste". "Eu ouvia aquilo, eu me impregnei daquilo tudo e fui trabalhando e compondo as músicas. As músicas eram levadas para o grupo e algumas eram rejeitadas, voltavam, eu trabalhava de novo". ${ }^{24}$ Em 2005, um episódio desse trabalho coletivo foi citado pelo compositor:

Eu lembro uma coisa engraçada que eles usam lá que é contra a chamada prosódia da música. Eles colocam a tônica da letra no lugar errado. Mas isto é muito, muito comum no Nordeste, como é muito comum em Cuba, por exemplo. Aí eu quis fazer assim. Depois as pessoas corrigiam. Eu falei, "mas não, é pra ser assim mesmo: 'Esta cova em que estás/ com palmos medida/ é a terrá que querias/ ver dividida/ é a terrá que querias/ver dividida"'. Então o pessoal depois corrigiu pra "é a terra que querias/ver dividida". ${ }^{25}$

Não tenho como avaliar o material pesquisado por Chico Buarque. Entretanto, em 1929, Mário de Andrade anotou um bendito em Catolé do Rocha, na

${ }^{23}$ A expressão é tomada de empréstimo a Mário de Andrade (cf. Mário de Andrade, "O samba rural paulista", in _. Aspectos da música brasileira, Belo Horizonte/Rio de Janeiro, Villa Rica, 1991, p. 179).

${ }^{24}$ Cf. Chico Buarque, "Eu já quis ser João Gilberto e Guimarães Rosa", in Santuza Cambraia Naves, Frederico Oliveira Coelho e Tatiana Bacal (org.) A MPB em discussão: entrevistas, Belo Horizonte, Editora da UFMG, 2006, p. 190. Entrevista realizada em 5 abr. 1999.

${ }^{25} \mathrm{Cf}$. Chico Buarque, Bastidores. Sobre a música cubana, cf. entrevista de Chico Buarque à revista Bizz, em abril de 1988. Versão eletrônica, disponível em: <www.chicobuarque.com.br>. Acesso em: 12 jan. 2005. 
Paraíba, ${ }^{26}$ no qual se contraria a prosódia em duas passagens, "Deus lhe paguiá santa esmola/ Deus o levi no andor":
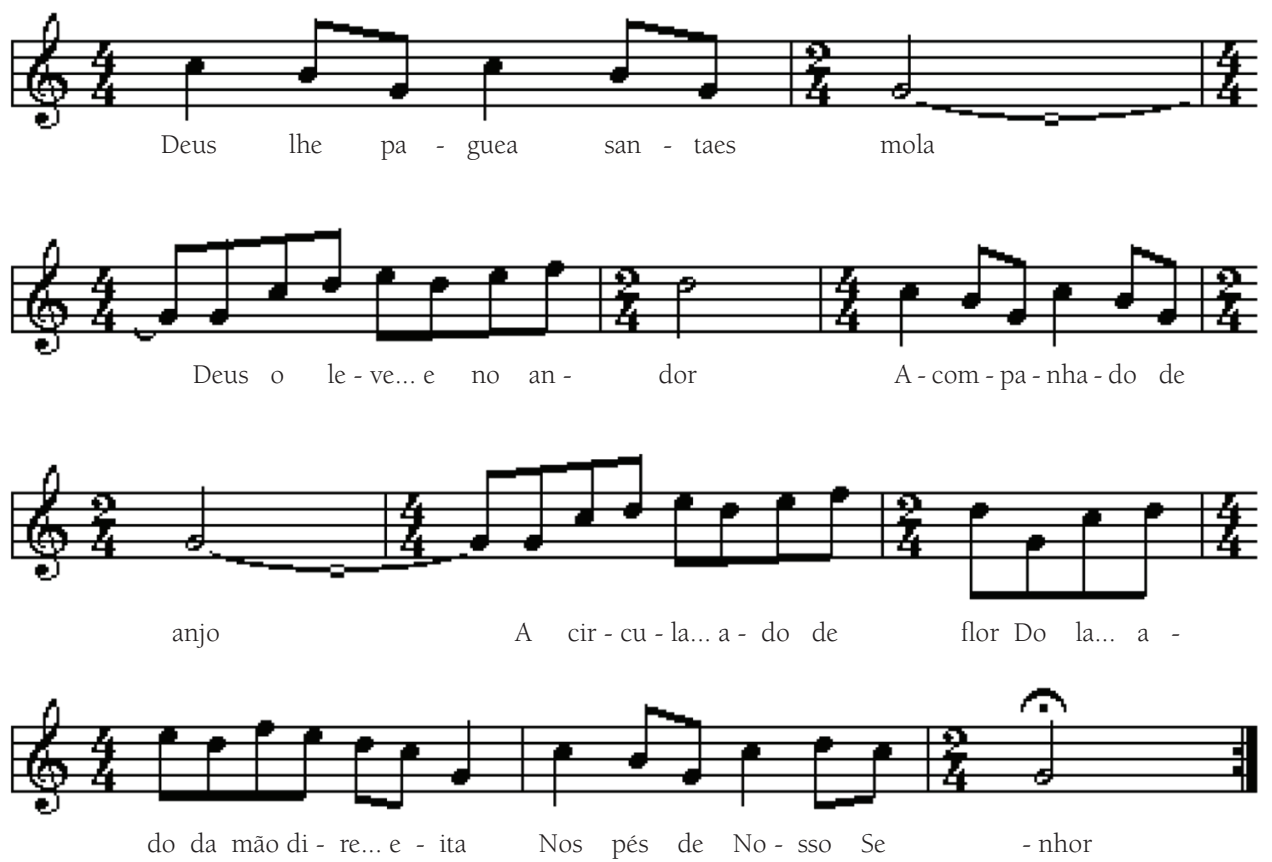

Figura 3 - Bendito anotado por Mário de Andrade em Catolé do Rocha.

Na crônica de O turista aprendiz em que relata a audição do bendito, Mário de Andrade nada observa sobre a prosódia. Mas o seu comentário indica que a música se impõe às palavras, e assim se justificam, de viés, as silabadas: "Termino de anotar a melodia e fico maravilhado contemplando a simplicidade genial dela. Que perfeição de linha, que equilíbrio de composição! E que desmentido pra certas teorias. Canto em maior e rápido e apesar disso duma dor magnífica, pobre, mesquinha, triste mesmo". Entre parênteses, o absurdo da situação de anotar a cantiga, alimentada com esmolas e entoada por "uma velha sentada no chão", maravilhando-se com a "voz nítida" e o equilíbrio musical da composição - o absurdo desta situação integra outra crônica, escrita ao final daquela viagem:

Mil cento e cinco quilômetros devorados. E uma indigestão formidável de amarguras, de sensações desencontradas, de perplexidades, de ódios. [...] Repugna minha sinceridade de homem

${ }^{26}$ Cf. Mário de Andrade, As melodias do boi e outras peças, preparação, introdução e notas de Oneyda Alvarenga, São Paulo, Duas Cidades; Brasília, Instituto Nacional do Livro, 1987, p. 194. 
fazer literatura diante desta monstruosidade de grandezas que é a seca sertaneja do Nordeste. Que miséria e quanta gente sofrendo... É melhor parar. Meu coração está penando por demais...27

Em Morte e vida severina, buscava-se uma tal adequação entre melodia e letra que alguns versos, segundo Chico Buarque, acabaram falados - ou mesmo cortados. Ao ser entrevistado pelo Pasquim, em 1975, o compositor recordou exemplos de ambos os casos:

Lembro de uma música no final, quando nascia a criança: "De sua formosura/ deixai-me que diga/ é belo como um coqueiro... Bom como caderno novo". Um verso não cabia de jeito nenhum. Convenci eles de colocarem uma atriz correndo de repente e dizendo o verso: (falando rapidamente) "Da sua formosura deixai-me que diga!". [...] E outras coisas que fomos cortando porque não cabiam na letra. Uma delas fiquei chateado depois, porque cortei sem pensar. Não tinha pensado mesmo. Era uma brincadeira, uma crítica, ao Gilberto Freyre. E eu não 'tava sabendo. Depois o João Cabral me perguntou por que eu tinha tirado. Realmente era porque não cabia na música. "...um mocambo modelar / como dizem os sociólogos do lugar." Mas eu não tinha ligado sociólogos a Gilberto Freyre. E "so-ció-lo-gos”... não dá. ${ }^{28}$

Sintetizando o que se viu, mas agora nos termos do modelo de análise desenvolvido por Luiz Tatit: "Funeral de um lavrador" se contrói na predominância da figurativização; as acentuações melódicas "se conformam às acentuações do texto, de modo a não prejudicar sua inteligibilidade", criando-se a impressão "de que a linha melódica poderia ser uma inflexão entoativa da linguagem verbal"; por consequência, o sentido de colóquio das quadras de João Cabral sai reforçado. No entanto, há recursos de passionalização decisivos para o rendimento da canção: saltos melódicos (ainda que localizados e comedidos), andamento desacelerado, investimento na duração de algumas notas. E não se deve menosprezar a pulsação, o leve balanço que é sustentado de forma regular pela percussão, mas que também atua no canto. A pulsação se liga diretamente à tematização, terceiro processo de compatibilização de melodia e letra estudado por Tatit. ${ }^{29} \mathrm{O}$ balanço da canção, com sua regularidade, atinge o corpo do ouvinte prescindindo da

${ }^{27}$ Mário de Andrade, O turista aprendiz, estabelecimento de texto, introdução e notas de Telê Porto Ancona Lopez, São Paulo, Duas Cidades/Secretaria da Cultura, Ciência e Tecnologia, 1976, p. 293 e 301. A primeira crônica é parcialmente transcrita por Oneyda Alvarenga em: Andrade, As melodias do boi e outras peças, op. cit., p. 330-331.

${ }^{28}$ Cf. Vários, O som do Pasquim, 1975. Versão eletrônica, disponível em: <www.chicobuarque. com.br>. Acesso em: 12 jan. 2005. Citando de memória, Chico Buarque alterou ligeiramente os versos: "De sua formosura/ deixai-me que diga:/ é belo como o coqueiro/ que vence a areia marinha"; "Ou como o caderno novo/ quando a gente principia"; "Cada casebre se torna/ no mocambo modelar/ que tanto celebram os/ sociólogos do lugar". No entando, curiosamente a transcrição da entrevista sugere a lembrança de "sociólogos" compondo uma redondilha maior: "so/ció/lo/gos/ do/ lu/gar/" (cf. Melo Neto, Morte e vida severina, op. cit., p. 196; 200-201).

${ }^{29}$ Cf. Luiz Tatit, A canção: eficácia e encanto, São Paulo, Atual, 1986, p. 11. Idem, O cancionista, São Paulo, Edusp, 1996, p. 20-24. 
compreensão abstrata das palavras. No limite, ao trabalhar com a canção, sempre haverá quem argumente que "constitui uma direção não-musical colocar o peso principal do interesse no texto". ${ }^{30}$

Em janeiro de 1992, Pablo, um médico argentino que então passava férias em Salvador, contou-me que "Funeral de um lavrador", cantada por Chico Buarque e o MPB4, era dançada nos bailinhos de sua adolescência na década de 1970, em Buenos Aires. Até que ele atentou ao significado de "funeral", e a canção foi excluída das vitrolas durante as festas. É lógico que essa anedota não indica que João Cabral se equivocara, sentindo-se satisfeito com a música de Morte e vida severina. Para além da óbvia barreira da língua, uma coisa é a canção gravada e difundida em meio a incontáveis produtos, outra coisa é a (mesma) canção ao vivo e articulada à narrativa de um espetáculo. Ainda assim, o que se pretende sublinhar, no exagero da anedota, é a capacidade da canção de também seduzir, fundamentalmente por seu ritmo musical, o ouvinte.

Essa é uma encruzilhada de várias questões para os cancionistas engajados na crítica social, no teatro ou em shows, na década de 1960 como hoje. Há a distração e o entorpecimento pelo ritmo musical, mas há também o valor mnemônico da canção. Há a necessidade de distanciamento crítico, tantas vezes ausente na famosa "esquerda festiva", mas há também a necessidade de mobilização do sujeito e de forças sociais num país em que comunidades organizam "o mundo pelo canto e pela dança", vivendo a "festa popular como experiência de outro tempo e lugar". ${ }^{31}$

No caso específico de "Funeral de um lavrador", a encruzilhada se adensa por algumas outras questões. Por um lado, o contato com a experiência social e econômica não se deu de forma imediata, mas com a mediação da literatura e do registro em fita de canções de tradição oral. Por outro, a poesia de João Cabral não permitiu o sentimentalismo demagógico, muito embora a gravação de Chico Buarque estabeleça o laço emocional da compaixão; e o trabalho coletivo no Tuca evitou a reprodução postiça de técnicas musicais (por exemplo, o canto contrário à prosódia).

Uma outra questão é que vigorava, em 1965, a "ideia equivocada de que a canção seria o agente da mudança histórica", de que a "desalienação das massas oprimidas" seria resolvida, pela classe média, "com violões". ${ }^{32}$ Mas, desde então,

${ }^{30}$ Utilizo livremente observação de Hegel acerca da música. Cf. G. W. F. Hegel, Cursos de estética, volume III, trad. Marco Aurélio Werle, Oliver Tolle; consultoria Victor Knoll, São Paulo, Edusp, 2002, p. 288.

${ }^{31}$ Cf. Lincoln Antonio, "São João no Maranhão". Traulito, São Paulo, n. 2, Companhia do Latão, jul./ago. 2010, p. 20.

${ }^{32}$ Cf. Gilberto Vasconcellos, "A musa popular brasileira (Da bossa-nova à cantiga de roda)", in Música popular: de olho na fresta, Rio de Janeiro, Edições do Graal, 1977, p. 89. Cf. Caetano Veloso, "Primeira feira de balanço", in O mundo não é chato, org. Eucanaã Ferraz, São Paulo, Companhia das Letras, 2005, p. 148. 
passou a vigorar uma prestigiada adesão à forma-mercadoria, num espectro que vai de sofisticados vermes sonoros (fórmulas simples que assombram o ouvinte, no limite do patológico) até atitudes de vanguarda em chave "nem sempre muito consequente e refletida". ${ }^{33}$ E esse ponto se desdobra na observação de que o período pós-1964 ficou marcado pelo "fenômeno da mercantilização da luta política", pela moda do esquerdismo, quando uma garota carioca se dizia "contra a censura, igual a todo mundo na praia", ou um fã pedia a Nara Leão, durante show em um clube de João Pessoa: "Agora, canta uma coisa subversiva pra nós". ${ }^{34}$ Mas atualmente as marcas históricas são outras. Além do fim da censura pelo aparelho de Estado e do calendário de eleições diretas, há a mobilidade do capital globalizado, o cada-um-por-si das relações de trabalho, a inclusão social pelos bens de consumo, a desintegração do ideário nacional-popular, o sucesso do marketing político. E há a moda de ostentar "um pensamento cada vez mais reacionário", no enquadramento da "indústria da glamourização" e do "medo da violência na classe média", conforme disse Chico Buarque em 2004: "Boutades às vezes racistas, preconceitos de classe, manifestações de desprezo mesmo pelos mais pobres se tornaram algo muito comum e socialmente valorizado". 35

Em 1976, o compositor respondia não saber muito bem por que a "alta burguesia" era uma parte de seu público: "Ela aceita e aplaude até as músicas que de certa forma a agridem, porque não se sente ameaçada". ${ }^{36}$ Contudo, por mais equivocada que tenha sido a inspiração revolucionária da chamada MPB, suas canções de protesto deram uma certa visibilidade a temas como o de "Funeral de um lavrador". ${ }^{37}$ Hoje em dia, não há dúvida de que a circulação da marca MPB, com seu selo de qualidade, transformou muito do engajamento político numa "musiquinha bem feita, bastante óbvia, que agrada como uma boa mobília". ${ }^{38}$ No entanto, os fatos sensibilizam cada vez menos ao ritmo atrofiado dos 140 caracteres.

${ }^{33}$ Cf. Marcos Napolitano, História E música: história cultural da música popular, Belo Horizonte, Autêntica, 2002, p. 68.

${ }^{34}$ Cf. Iná Camargo Costa, A hora do teatro épico no Brasil, Rio de Janeiro, Paz e Terra/Graal, 1996, p. 111. Cf. Regina Zappa, Chico Buarque: para todos, 2. ed., Rio de Janeiro, Relume Dumará/ Prefeitura, 1999, p. 98. Cf. Sérgio Cabral, Nara Leão: uma biografia, op. cit., p. 128.

35 Cf. Chico Buarque, "O tempo e o artista: 'Querem exterminar os pobres do Rio"'. Versão eletrônica, disponível em: <http://wwwl.folha.uol.com.br/fsp/ilustrad/fq2612200409.htm>. Acesso em: 6 jan. 2005. Publicado originalmente na Folha de S.Paulo em 26 dez. 2004.

${ }^{36}$ Cf. "Entrevista: Chico Buarque". Revista 365, São Paulo, n. 2, ABZ, p. 301, s. d. Versão eletrônica, "Revista 356 - 1976", disponível em: <www.chicobuarque.com.br>. Acesso em: 12 jan. 2005.

${ }^{37}$ Inspiro-me em Marilena Chauí, "Um modo mágico de invocar a marcha da história", in História da música popular brasileira: Grandes compositores: Carlos Lyra, Bôscoli \& Menescal, São Paulo, Editora Abril, 1982, p. 7-8; e em passagem de Roberto Schwarz, "Nacional por subtração", in Que horas são? São Paulo, Companhia das Letras, 1986, p. 34.

${ }^{38}$ Cf. Lincoln Antonio, “+ personagem”, Folha de S.Paulo, caderno Mais, 25 mar. 2001, p. 3. 
Em 24 de maio de 2011, José Claudio Ribeiro da Silva e Maria do Espírito Santo da Silva, trabalhadores rurais e líderes ambientalistas, foram assassinados. O casal vivia em um assentamento agroextrativista na Amazônia. Cada um deles teve parte das orelhas cortada, sinal de crime por encomenda. É evidente que canções para teatro não impediriam mortes desse tipo, é evidente que não resolvem impasses como o da questão agrária no Brasil. Mas também é evidente que isso não quer dizer que não se possa cantar uma experiência brutal e contribuir para o seu esclarecimento. 